\title{
Effects of Biochar and Compost on Mung Bean Growth and Soil Properties in a Semi-arid Area of Northeast China
}

\author{
Gui-Jun Wang, ${ }^{1,2}$ Zhen-Wen $\mathrm{Xu}^{2}$ and $\mathrm{Yu} \mathrm{Li}^{1,3^{*}}$ \\ ${ }^{1}$ College of Life Sciences, Northeast Normal University, Changchun, Jilin 130024, China \\ ${ }^{2}$ College of Urban and Environmental Sciences, Changchun Normal University, Changchun, Jilin 130032, China \\ ${ }^{3}$ Engineering Research Center of Chinese Ministry of Education for Edible and Medicinal Fungi, Jilin Agricultural University, \\ Changchun, Jilin 130118, China \\ *For correspondence: yuli966@126.com
}

\begin{abstract}
Five treatments were performed to examine the effects of biochar and compost, applied separately or in combination, on plant growth of mung bean (Vigna radiata) and soil properties in a semi-arid area of northeast China. The results showed that biochar and compost produced positive impacts on both the plants and the soil, with these effects dependent upon the biochar to compost ratios. In addition, the changes in biomass and growth indices vary according to the growing phases: with the medium to late growing phases showing more prominent responses than the early phase. The total organic carbon and electric conductivity were increased by the soil amendments, especially in the biochar-compost combination treatments $(\mathrm{P}<0.05)$. Addition of biochar-compost lowered the soil bulk density relative to the control $(\mathrm{P}<0.05)$. Also notably, the biochar-compost treatment enhanced the water holding capacity, which is highly desirable for sandy soils. In short, synergic effects of biochar and compost were documented in promoting plant growth, biomass accumulation, yield and in improving soil properties. (C) 2016 Friends Science Publishers
\end{abstract}

Keywords: Physical-chemical properties; Synergism; Biochar; Compost; Water holding capacity; Yield

\section{Introduction}

Desertification is becoming a global problem, and this is especially the case for farmland, threatening food security of large proportions of the world population. Sandy soils are susceptible to wind erosion and evaporation, severely compromising the productivity of agricultural crops. To deal with this issue effectively, we are inspired by the practice of the pre-Columbia people who left behind sustainably fertile soils well known as terra preta ("black earth" in Portuguese), rich in organic matter and nutrients, achieved by adding charred residues (biochar) along with animal excrements and household wastes; this ancient technique could serve as a model for today's sustainable agriculture (Schulz and Glaser, 2012). Biochar, representing plant biomass-derived materials contained within the black carbon continuum (Warnock et al., 2007), can increase the water holding capacity of sandy or arid soils (Bonelli and Ramos, 2006). Dugan et al. (2010) showed that a certain rate of maize stover biochar increased the water holding capacity of sandy soil by $349-481 \%$. This is possible simply owing to the fact that the specific surface area of biochar is thousands of times higher than that of the sandy soil particles.

Another line of research has focused on the beneficial potentials of utilizing compost. It has been demonstrated that compost is able to improve soil physical properties; examples of such benefits include reduced bulk density, lowered erosion, increased aggregation stability (Kong et al., 2005), higher available water holding capacity (Carter et al., 2004; Evanylo et al., 2008), larger pore volumes and better hydraulic conductivity (Carter et al., 2004). Compost is also helpful in improving soil chemical properties concerning nutrient levels, cation exchange capacity (Ouédraogo et al. 2001) etc. As a manifestation of all these advantages, compost improves growth, productivity and quality of agricultural crops (Lehmann et al., 2003).

However, little is known about biochar-compost interactions, especially about whether they have synergisms in influencing the availability of soil nutrients in sandy soil, leading to increases of plant growth and crop yield. The objective of this study was to examine the effects of biochar and compost as applied separately vs. in combination in a semi-arid area of northeast China.

\section{Materials and Methods}

\section{The Experimental site}

The experimental site is located in She-li County 
$\left(45^{\circ} 33^{\prime} 44^{\prime \prime} \mathrm{N}, 123^{\circ} 22^{\prime} 66^{\prime \prime} \mathrm{E}\right)$, Da'an City, Jilin Province, northeast China. The annual precipitation in this area is 420 $\mathrm{mm}$, typical for a semi-arid climate zone. The soil is of the sandy loam type, which contains medium sand (1.00-0.25 $\mathrm{mm})$ 9.45-20.50\%, fine sand $(0.25-0.001 \mathrm{~mm}) 63.61-$ $77.49 \%$, and clay $(<0.001 \mathrm{~mm}) 9.94-13.06 \%$. The soil properties are as follows: available nitrogen, $34.92 \mathrm{ppm}$; available phosphorus, $2.33 \mathrm{ppm}$ (P-poor); available potassium, 83.80 ppm (K-rich); organic carbon (TOC), 3.60 $\mathrm{g} / \mathrm{kg}$; electronic conductivity (EC), $91.45 \mu \mathrm{s} / \mathrm{cm} ; \mathrm{pH}, 8.75$.

\section{Soil Treatments with Biochar and Compost}

Biochar was obtained from Biochar Research Center of Shenyang Agriculture University, which was produced from corn stalk charred anoxically at $450^{\circ} \mathrm{C}$ in a furnace (Chen, 2007). Its total $\mathrm{C}, \mathrm{N}$ and $\mathrm{S}$ contents were $65.78 \%, 1.56 \%$ and $0.653 \%$, respectively. Other parameters are: surface area, $1.332 \mathrm{~m}^{2} \mathrm{~g}^{-1} ; \mathrm{pH}, 8.82$; cation exchange capacity, $15.96 \mathrm{cmol}_{\mathrm{c}} \mathrm{kg}^{-1}$; and ash content, $17.54 \%$.

The compost used was pig manure near the experimental area. Element composition: C, 22.68\%; N, $2.45 \%$; P, 0.896\%; and K, $1.429 \%$.

A medium-sized field study was designed with the following five treatments (each with three replicates), all without inorganic fertilizer added: "CN" (control, no biochar and compost added); " $\mathrm{BC}_{10}$ " (10 t ha ${ }^{-1}$ biochar); "CP" (20 t ha ${ }^{-1}$ compost); "BC $5+\mathrm{CP}^{2}$ " $\left(5 \mathrm{t} \mathrm{ha}^{-1}\right.$ biochar $+20 \mathrm{t}$ $\mathrm{ha}^{-1}$ compost $)$; "BC $10+\mathrm{CP}$ " (10 t ha- biochar $+20 \mathrm{t} \mathrm{ha} \mathrm{ha}^{-1}$ compost). A total of 15 plots were included, each being 8 $\mathrm{m} \times 8 \mathrm{~m}$ (soil depth: $15 \mathrm{~cm}$ ), with a $1-\mathrm{m}$ isolation belt between neighboring plots. For each treatment, the amendments were mixed evenly in the respective plots by a rot cultivator 3 times on May 1, 2013, and incubated for one month before sowing of seeds.

\section{Experimental Methods}

Hand-selected seeds of mung bean (Vigna radiata) were sowed on May 30, 2013 at a row space of $60 \mathrm{~cm}$ and a cave space of $10 \mathrm{~cm}$, with 80 seeds each row for a total of 13 rows per plot. About 20 days after sowing, thinning was performed so that 40 seedlings were maintained for each row to maturity. Growth indices (plant height, stem diameter and root length) were collected at multiple time points (for 10 plants per plot). Chlorophyll concentrations of leaves were measured using an SPAD-502 chlorophyll tester. The dry biomass, the 1000-kernel weight and single plant yield were all measured for randomly chosen 15 plants from each plot, after a $24-\mathrm{h}$ oven-drying at $70^{\circ} \mathrm{C}$. The field yield per hectare was estimated using the following formula: SPY $\times$ $490 \times 10000 \mathrm{~m}^{2} / 8 \mathrm{~m} \times 8 \mathrm{~m}$. Where: SPY is mean single plant yield and 490 is the number of plants per plot at the harvest time.

Before the experiment and after harvesting, five soil cores (each $5 \mathrm{~cm}$ in diameter and $15 \mathrm{~cm}$ in depth) from each plot were obtained with boring augers. After air-drying, physical and chemical properties of the soil samples were examined. Soil pH (soil: water is 1:5) and EC (soil: water is 1:5) were read with a $\mathrm{pH}$ meter (PHS-3C) and EC meter (DDS-307a), respectively. The total OC was analyzed using the Potassium Dichromate Oxidation method. Total nitrogen contents were determined by the Kjeldah method. A 100 $\mathrm{cm}^{3}$ of undisturbed soil sample was collected by soil cutting rings, then oven dried at $105^{\circ} \mathrm{C}$ for $12 \mathrm{~h}$, and weighed, for calculating soil bulk density. The oven-dried soil cutting rings were left in a tray containing water for $24 \mathrm{~h}$, followed by draining for $2 \mathrm{~h}$, and weight was taken to determine the water holding capacity (WHC) of the soil samples.

ANOVA was conducted to determine the differences between treatments. Significant differences were tested using LSD at 5\% level and 1\% level. All figures were generated using Sigma Plot 10.0 software.

\section{Results}

\section{Effects of Soil Amendment on Mung Bean Biomass and Yield}

The biomass data for all treatments were displayed in Fig. 1, for the three time points examined: early growing phase (about 30 days after sowing, DAS); medium growing phase (about 50 DAS); and harvest time (100 DAS). During the early growing phase, there were no significant differences between amendment-treatments and the control. During the medium growing phase, biomasses were significantly higher in the amendment-treatments than in the control $(\mathrm{P}<0.01)$, with the highest biomass in the " $\mathrm{BC}_{10}+\mathrm{CP}$ " group (both for the aboveground and underground portions), followed (in a decreasing order) by the " $\mathrm{BC}_{5}+\mathrm{CP}$ ", "CP" and " $\mathrm{BC}_{10}$ " treatments. During the harvest time, the gaps among the various treatments were not as prominent, with biomasses of the " $\mathrm{BC}_{5}+\mathrm{CP}$ " and " $\mathrm{BC}_{10}+\mathrm{CP}$ " treatments significantly higher than the control $\left(\mathrm{P}<0.05\right.$; the " $\mathrm{BC}_{5}+\mathrm{CP}$ " treatment showing the highest value), while the " $\mathrm{BC}_{10}$ " treatment had no significant effect on the biomass of plant (both aboveground and underground portions) over the control.

The field yield data exhibited a similar pattern (Table 1). The " $\mathrm{BC}_{10}+\mathrm{CP}$ " treatment gave rise to the highest field yield, followed (in a decreasing order) by " $\mathrm{BC}_{5}+\mathrm{CP}$ ", " $\mathrm{CP}$ " and " $\mathrm{BC}_{10}$ ", with increases (over the control) by $134.86 \%$, $118.21 \%, 86.48 \%$ and $52.73 \%$, respectively. The 1000 kernel weight of the " $\mathrm{BC}_{5}+\mathrm{CP}$ " group was the highest and also significantly different from the control $(\mathrm{P}<0.05)$, while the " $\mathrm{BC}_{10}+\mathrm{CP}$ " and "CP" treatments appeared higher than the control, yet not in significant level. The " $\mathrm{BC}_{10}$ " treatment appeared slightly lower than the control, but not in significant level.

In short, the " $\mathrm{BC}_{10}+\mathrm{CP}$ " treatment had the highest contribution to the yield, while the " $\mathrm{BC}_{5}+\mathrm{CP}$ " treatment had the highest contribution to the kernel weight as well as the biomass of the crop. 
Table 1: The net thousand kernel weight and estimated yield of mung bean

\begin{tabular}{lll}
\hline Treatment & 1000-kernel weight $(\mathrm{g})$ & Yield $\left(\mathrm{kg} \mathrm{ha}^{-1}\right)$ \\
\hline $\mathrm{CP}$ & 58.5347 & $1351.2^{*}$ \\
$\mathrm{BC}_{10}$ & 57.4723 & $1106.7^{*}$ \\
$\mathrm{BC}_{10}+\mathrm{CP}$ & 62.4863 & $1701.8^{* *}$ \\
$\mathrm{BC}_{5}+\mathrm{CP}$ & $63.4320^{*}$ & $1581.2^{* *}$ \\
$\mathrm{CN}$ & 57.2490 & 724.6 \\
$\mathrm{SE}$ & 1.0432 & 112.91 \\
\hline${ }^{\mathrm{z}} \mathrm{SE}:$ standard error of the mean; ${ }^{*}$ The mean difference is significant from \\
the control at the 0.05 level; ${ }^{* *}$ The mean difference is significant from the \\
control at the 0.01 level
\end{tabular}

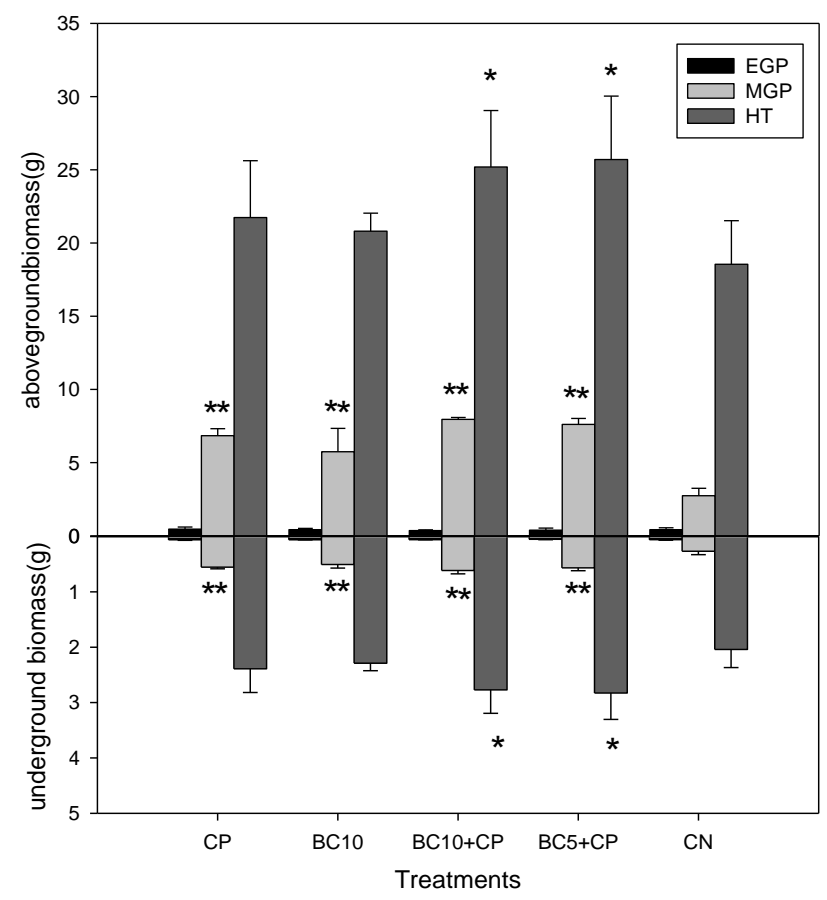

Fig. 1: Biomass of mung bean in three growing phases. EGP: Early growing phase, MGP: Medium growing phase, HT: Harvest time. *indicates statistically different $(P<0.05)$ for the same parameter in same growing period. ** indicates statistically extremely different $(P<0.01)$

\section{Effect of Soil Amendments on the Growth of Mung Bean}

The growth indices of Mung bean collected at the three time points were provided in Fig. 2. While the main roots in the amendment treatments were longer than in the control, only the " $\mathrm{BC}_{10}+\mathrm{CP}$ " resulted in a significant difference at the 0.05 level. The amendment treatment increased stem diameters mung bean plants, a trend becoming increasingly obvious with the progression of plant growth. For example, in the " $\mathrm{BC}_{5}+\mathrm{CP}$ " and " $\mathrm{BC}_{10}+\mathrm{CP}$ " treatments, the stems were significantly thicker than those in the control during the early growing phase $(\mathrm{P}<0.05)$; this trend became further expanded during the late growing phase. Effects on plant height is a different scenario: during the earlier growing phase, not significant differences were observed, but amendment treatments were found to have significant promoting functions in the late growing phase.

Chlorophyll contents in all amendment treatments were higher in the control during the medium growing phase, and all combination treatments resulted higher chlorophyll contents than the single applications (biochar/compost). However, with the spreading of leaves, the gaps were narrowed down, with values from only the combination treatments significantly higher than the control $(\mathrm{P}<0.05)$.

\section{The Effect of Soil Amendments on the Physical and Chemical Properties of the Sandy Soil}

Addition of amendments did not significantly affect either the total $\mathrm{N}$, available $\mathrm{N}, \mathrm{K}$ or the $\mathrm{pH}$ level of the soil (Tables 2 and 3), while the $\mathrm{pH}$ level in " $\mathrm{BC}_{10}$ " treatment was higher than others, but not in significant level. The available $\mathrm{P}$ in " $\mathrm{BC}_{5}+\mathrm{CP}$ " and " $\mathrm{BC}_{10}+\mathrm{CP}$ " treatments were higher significantly than in the control. The EC values were significantly different between all amendment treatments and the control. The TOC in the " $\mathrm{BC}_{10}$," " $\mathrm{BC}_{5}+\mathrm{CP}$ " and " $\mathrm{BC}_{10}+\mathrm{CP}$ " treatments were significantly higher than in the control. It can be seen from Table 3 that the " $\mathrm{BC}_{10}+\mathrm{CP}$ " treatment led to the highest increase in WHC (being 5.44\% higher than the control, $\mathrm{P}<0.05$ ) and the specific gravity had no significant differences among the treatments. The bulk density declined in all amendment treatment, showing a from-high-to-low order as follows: "CN", "CP", " $\mathrm{BC}_{10}$ ", "CP", " $\mathrm{BC}_{5}+\mathrm{C}$ ", "BC $10+\mathrm{CP}$ ", with the lowest level in " $\mathrm{BC}_{10}+\mathrm{CP}$ " and " $\mathrm{BC}_{5}+\mathrm{CP}$ " treatments, both being significant lower than the $\mathrm{CN}(\mathrm{P}<0.05)$.

\section{Discussion}

Our results showed that addition of soil amendments increased plant growth, biomass and yield of mung bean. It is interesting that although this enhancement is characterized by a biochar-compost synergic effect; that is, the " $\mathrm{BC}_{5}+\mathrm{CP}$ " and " $\mathrm{BC}_{10}+\mathrm{CP}$ " treatments promoted more growth than "CP" or " $\mathrm{BC}_{10}$ " alone. We further noticed that both the biomass and growth responded differently according to the growing phases; Briefly, plant heights were not significantly different among the various treatments during the early growing phase, but they became more significantly differently from the medium growing phase on. This pattern could be attributable to the slow nutrient releasing feature of biochar and compost. For mung bean, as a grain crop, the correlation between yield increase and soil amendments is of particular importance. Our estimated $\mathrm{kg} \mathrm{ha}^{-1}$ values for the " $\mathrm{BC}_{10}+\mathrm{CP}$ ", "BC $5+\mathrm{CP}$ " and "CP" treatments were 1701.8, 1581.2 and 1351.2, respectively all above the national average mung bean yield (1285.5 kg ha-1) in 2010 (Liu, 2012). This finding strongly validates the long-claimed benefits of biochar and compost, especially when applied 
Table 2: Nutrient indices of soil in different treatments ${ }^{\mathrm{z}}$

\begin{tabular}{lllll}
\hline Treatment & Available nitrogen $(\mathrm{ppm})$ & Total N $\left(\mathrm{g} \mathrm{kg}^{-1}\right)$ & Available phosphorus $(\mathrm{ppm})$ & Available potassium $(\mathrm{ppm})$ \\
\hline $\mathrm{CP}$ & 37.2367 & 0.5588 & 3.6833 & 85.9633 \\
$\mathrm{BC}_{10}$ & 34.8800 & 0.6821 & 3.1367 & 84.1900 \\
$\mathrm{BC}_{10}+\mathrm{CP}$ & 45.3500 & 0.6830 & $5.6033^{*}$ & 9.6505 \\
$\mathrm{BC}_{5}+\mathrm{CP}$ & 41.9467 & 0.5946 & $5.2733^{*}$ & 92.0833 \\
$\mathrm{CN}$ & 35.3500 & 0.5569 & 2.2033 & 89.8067 \\
$\mathrm{SE}$ & 5.2451 & 0.0332 & 0.5354 & 83.9100 \\
\end{tabular}

${ }^{\text {z }} \mathrm{SE}=$ standard error of the mean; ${ }^{*}$ The mean difference is significant with control at the 0.05 level

Table 3: Physical-chemical properties of soil in different treatments $^{\mathrm{z}}$

\begin{tabular}{llllll}
\hline Treatment & $\mathrm{pH}$ & $\mathrm{EC}(\mu \mathrm{s} / \mathrm{cm})$ & $\mathrm{WHC}(\%)$ & $\mathrm{SG}\left(\mathrm{g} / \mathrm{cm}^{3}\right)$ & $\mathrm{BD}\left(\mathrm{g} / \mathrm{cm}^{3}\right)$ \\
\hline $\mathrm{CP}$ & 8.8033 & $109.800^{*}$ & 39.9700 & 2.5989 & 1.5400 \\
$\mathrm{BC}_{10}$ & 8.8600 & $110.067^{*}$ & 39.8434 & 2.6058 & 1.5247 \\
$\mathrm{BC}_{10}+\mathrm{CP}$ & 8.8467 & $120.867^{* *}$ & $41.8634^{*}$ & 2.5906 & $1.5147^{*}$ \\
$\mathrm{BC}_{5}+\mathrm{CP}$ & 8.8400 & $115.200^{* *}$ & 40.4966 & 2.6136 & $1.5153^{*}$ \\
$\mathrm{CN}$ & 8.8167 & 94.463 & 39.7034 & 2.6067 & 1.5900 \\
$\mathrm{SE}$ & 0.0083 & 3.4909 & 0.3238 & 0.0257 & 0.0117 \\
\hline
\end{tabular}

${ }^{z}$ SE: standard error of the mean. WHC: water holding capacity; SG: specific gravity; BD: bulk density. ${ }^{*}$ The mean difference is significant relative to the control at the 0.05 level. ${ }^{* *}$ The mean difference is significant relative to the control at the 0.01 level

in combination, in improving the quality of sandy soils. As another line of support for this conclusion, we found that chlorophyll contents of mung bean leaves from amendment treated groups were higher than in the control; this could lead to more effective photosynthesis.

When the soil physical-chemical properties were examined, we noticed that the influence of the amendment treatments is a complicated issue. Although the $\mathrm{pH}$, the total $\mathrm{N}$, available $\mathrm{N}$ and $\mathrm{K}$ did not show significant differences between the amendment treatments and the control, the available $\mathrm{P}$ in " $\mathrm{BC}_{5}+\mathrm{CP}$ " and " $\mathrm{BC}_{10}+\mathrm{CP}$ " treatments were higher significantly than in the control. The small different of $\mathrm{pH}$ level between $\mathrm{BC}$ and non $\mathrm{BC}$ treatment may because the high $\mathrm{pH}$ background of the test soil. The WHC, TOC and available $\mathrm{P}$ concentration of soil were increased with biochar applied alone or in combination with compost. The bulk density declined with the addition of amendments, especially when biochar and compost were applied together. Earlier, it was reported that biochar by itself will not contribute meaningful amounts of nutrients given its high stability (Granatstein et al., 2009; Tammeorg et al., 2014); hence, biochar applications have been considered as supplying soil conditioners rather than nutrients (Steiner et al., 2007). However, due to its high carbon content, biochar can bring up the TOC levels of the soil.

Water is another major parameter influencing soil quality, especially for sandy soil. Arid or semi-arid soils have very low water holding capacities (WHC), limiting plant growth and yield production; therefore, increasing WHC could potentially improve crop yields in areas with these soil types (Suzette et al., 2011). Many studies have shown a positive correlation between applications of biochar and/or compost and enhanced WHC (Tryon, 1948; Glaser, 2002;

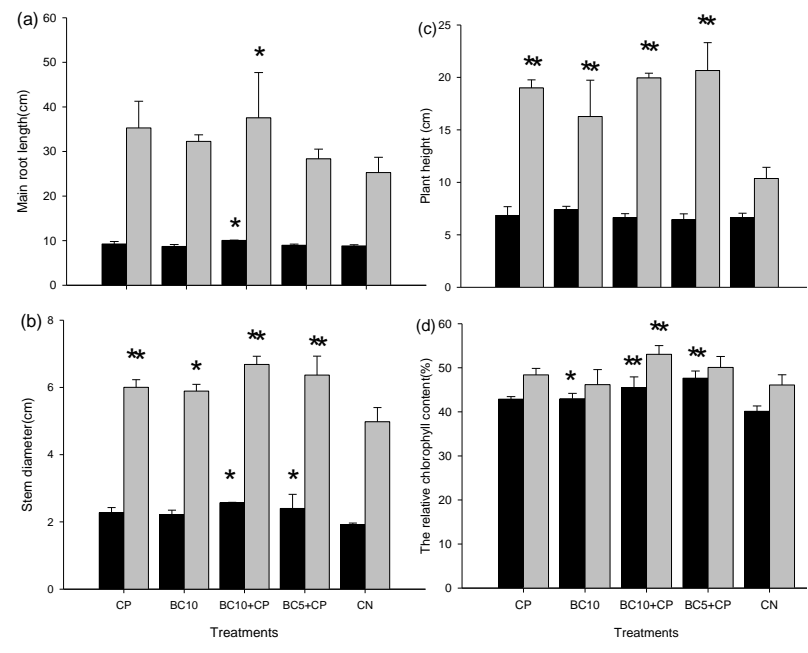

Fig. 2: The growth indices of mung bean during different growing phases. (a) main root diameter, (b) stem diameter, (c) plant height; and (d) the relative chlorophyll content. The black bars indicate in early growing phase; the grey bars indicate late growing phase (about 80 days after sowing). "indicates statistically different $(P<0.05)$ for the same parameter in the same growing period. ${ }^{* *}$ indicates statistically extremely different $(P<0.01)$

Cheng et al., 2006; Laird, 2008; Dugan et al., 2010). In the present study, we did observe a biochar-compost synergistic effect for water retention in sandy soils. This is conceivable, because biochar decomposition rates and overall surface reactivity would increase as long as compost is available. Hence, with a continuous nutrient supply from the compost, biochar which acts as a soil conditioner will significantly improve soil tilth, productivity, nutrient retention and availability to the growing plants (Glaser, 2002).

\section{Conclusion}

Combined compost and biochar is likely to have a number of benefits compared to mere mixing of biochar or compost with soil. Soil amendments with biochar and compost exhibited synergic effects on plant growth, biomass accumulation and yield production of mung bean, and these effects are related to the improved soil properties. It should be noted that biochar and compost combined in different ratios resulted in wide ranges of changes on both the plant 
and the soil sides. Also, the synergism mechanism impact of biochar and compost was not clear until now, so more research are needed for testing the affection of different soil amendments on the plant growth, yield, health and the soil properties, contamination cleanup and so on in future.

\section{Acknowledgements}

The first author acknowledges the financial grant from National Natural Science Foundation of China (No. 31200419) and Science and Technology Foundation of Jilin Education Department (No. 2015-366). Thanks for Prof. Hui-qing Liu's guide on the experiment design and Prof. Feng-shan Ma's help on the language improvement.

\section{References}

Bonelli, P.R. and M.E. Ramos, 2006. Potentialities of the biochar generated from raw and acid pre-treated sugarcane agricultural wastes. $8^{\text {th }}$ AsiaPacific International Symposium on Combustion and Energy Utilization. October 10-12, 2006, Russian Federation, Sochi, Russia

Carter, M.R., J.B. Sanderson and J.A. MacLeod, 2004. Influence of compost on the physical properties and organic matter fractions of a fine sandy loam throughout the cycle of a potato rotation. Can. J. Soil. Sci., 84: 211-218

Cheng, C.H., J. Lehmann, J.E. Thies, S.D. Burton and M.H. Engelhard, 2006. Oxidation of black carbon by biotic and abiotic processes. Org. Geochem., 37: 1477-1488

Dugan, E., A. Verhoef, S. Robinson and S. Sohi, 2010. Bio-char from sawdust, maize stover and charcoal: Impact on water holding capacities (WHC) of three soils from Ghana. Proceedings of the $19^{\text {th }}$ World Congress of Soil Science: Soil Solutions for a Changing World, 4.2.2 Soil and Water - Global Change, pp: 1-12; 1-6 August 2010. Brisbane, Australia

Evanylo, G., C. Sherony, J. Spargo, D. Starner, M. Brosius and K. Haering, 2008. Soil and water environmental effects of fertilizer-, manure-, and compost-based fertility practices in an organic vegetable cropping system. Agric. Ecosys. Environ., 127: 50-58
Glaser, B., J. Lehmann and W. Zech, 2002. Ameliorating physical and chemical properties of highly weathered soils in the tropics with charcoal - a review. Biol. Fert. Soils, 35: 219-230

Granatstein, D., C.E. Kruger and H. Collins, 2009. Use of Biochar from the Pyrolysis of Waste Organic Material as a Soil Amendment. Final Project Report. Center for Sustaining Agriculture and Natural Resources, Washington State University, Wenatchee, Washington, USA

Kong, A.Y., J. Six, D.C. Bryant, R.F. Denison and C.V. Kessel, 2005. The relationship between carbon input, aggregation, and soil organic carbon stabilization in sustainable cropping systems. Soil Sci. Soc. Amer. J., 69: 1078-1085

Laird, D.A., 2008. The charcoal vision: A win-win-win scenario for simultaneously producing bioenergy, permanently sequestering carbon, while improving soil and water quality. Agron. J., 100: 178181

Lehmann, J., J.P. Silva, C. Steiner, T. Nehls, W. Zech and B. Glaser, 2003. Nutrient availability and leaching in an archaeological Anthrosol and a Ferralsol of the Central Amazon basin: fertilizer, manure and charcoal amendments. Plant Soil, 249: 343-357

Liu, H., 2012. The product situation and development prospect of mung bean in China. Biotechnol. Bull., 6: 36-39

Schulz, H. and B. Glaser, 2012. Effects of biochar compared to organic and inorganic fertilizers on soil quality and plant growth in a greenhouse experiment. J. Plant. Nutr. Soil. Sci., 175: 410-422

Steiner, C., W.G. Teixeira, J. Lehmann, T. Nehls, J.L.V. Macêdo, W.E.H. Blum and W. Zech, 2007. Long term effects of manure, charcoal and mineral fertilization on crop production and fertility on a highly weathered central Amazonian upland soil. Plant Soil, 291: 279-290

Suzette, P.G., K.Y. Jonathan and G. David, 2011. The economic value of biochar in crop production and carbon sequestration. Energy Policy, 39: 6344-6350

Tammeorg, P., A. Simojoki, P. Mäkelä, F.L. Stoddard, L. Alakukku and J. Helenius, 2014. Biochar application to a fertile sandy clay loam in boreal conditions: effects on soil properties and yield formation of wheat, turnip rape and faba bean. Plant Soil, 374: 89-107

Tryon, E.H., 1948. Effect of Charcoal on Certain Physical, Chemical, and Biological Properties of Forest Soils. Ecol. Monogr., 18: 81-115

Warnock, D.D., J. Lehmann, T.W. Kuyper and M.C. Rillig, 2007. Mycorrhizal responses to biochar in soil-concepts and mechanisms. Plant Soil, 300: 9-20

(Received 23 June 2016; Accepted 11 July 2016) 